\title{
Detection of New Ethylene-Producing Bacteria, Pseudomonas syringae pvs. cannabina and sesami, by PCR Amplification of Genes for the Ethylene-Forming Enzyme
}

\author{
M. Sato, K. Watanabe, M. Yazawa, Y. Takikawa, and K. Nishiyama
}

First, second, and third authors: National Institute of Sericultural and Entomological Science, Tsukuba, Ibaraki 305, Japan; fourth author: Faculty of Agriculture, Shizuoka University, Ohya, Shizuoka 422, Japan; fifth author: National Institute of Agro-Environmental Sciences, Tsukuba, Ibaraki 305, Japan.

Accepted for publication 31 August 1997.

\begin{abstract}
Sato, M., Watanabe, K., Yazawa, M., Takikawa, Y., and Nishiyama, K. 1997. Detection of new ethylene-producing bacteria, Pseudomonas syringae pvs. cannabina and sesami, by PCR amplification of genes for the ethylene-forming enzyme. Phytopathology 87:1192-1196.

Strains of Pseudomonas syringae (78 strains and 43 pathovars) and other strains (79) of plant and insect origin were examined for the presence of the ethylene-forming enzyme gene (efe) by polymerase chain reaction (PCR) assay. The sequence of the efe gene of $P$. syringae pv. phaseolicola PK2 was used to design two primer sets for amplification of the gene. In addition to $P$. syringae pv. phaseolicola (the "kudzu strain") and $P$. syringae pv. glycinea, which were efficient ethylene producers,

several strains of $P$. syringae pvs. sesami and cannabina generated PCR products of the predicted size. A DNA probe of the efe gene, isolated from strain PK2, hybridized to these PCR products, indicating homology to the P. syringae pv. phaseolicola efe gene. PCR restriction fragment length polymorphism analyses suggested that these four pathovars harbor a similar $e f e$ gene. Furthermore, the probe hybridized to an indigenous plasmid of $P$. syringae pv. cannabina, suggesting that the efe gene could be located on a plasmid in this pathovar, but did not hybridize to plasmids of $P$. syringae pv. sesami strains. $P$. syringae pvs. sesami and cannabina strains produced ethylene in King's medium B at levels similar to those of $P$. syringae pvs. phaseolicola and glycinea. Thus, two new ethylene-producing bacteria were detected by the PCR assay.
\end{abstract}

Ethylene is a plant hormone involved in regulation of numerous physiological processes. Ethylene also is produced by microorganisms, including a limited number of plant-pathogenic bacteria. Goto et al. (6) reported that "kudzu strains" of Pseudomonas syringae pv. phaseolicola produce ethylene very efficiently and are considered to be among the most efficient ethylene-producing microorganisms. Sato et al. (16) reported that all the strains of $P$. syringae pv. glycinea also are very efficient ethylene producers. More recently, Weingart and Volksch (18) confirmed the ethyleneproducing ability of strains of $P$. syringae pvs. phaseolicola (kudzu strain) and glycinea. No other plant-pathogenic bacteria produce ethylene as efficiently, although several species, including Ralstonia solanacearum and $P$. syringae pv. pisi, produce a small amount of ethylene $(3,16,17)$. Although the role of ethylene in pathogenicity has not yet been determined, Weingart and Volksch (18) recently showed that these strains produce ethylene in planta, indicating a potential role in pathogenicity. The study of new ethylene-producing bacteria could yield information about the role or evolution of ethylene production in plant-pathogenic bacteria.

In microorganisms, ethylene is produced either via 2-keto-4methylthibutyric acid, a transaminated derivative of methionine, by an NADH:Fe(III)EDTA oxidoreductase-mediated reaction, or 2-oxoglutarate, by an ethylene-forming enzyme. The latter biosynthesis process is found in P. syringae pvs. phaseolicola and glycinea $(5,9,10)$. Recently, the efe gene of $P$. syringae pv. phaseolicola PK2 was cloned and sequenced by Fukuda et al. (4), who indicated that it is borne on indigenous plasmids in $P$. syringae pvs. phaseolicola and glycinea (11). These findings suggest that

Corresponding author: M. Sato; E-mail address: satomamo@ss.nises.affrc.go.jp

Publication no. P-1997-0929-03R

(C) 1997 The American Phytopathological Society horizontal transmission of the efe gene has occurred between bacterial strains and pathovars. Furthermore, Weingart and Volksch (18) revealed that polymerase chain reaction (PCR) amplification of a portion of the efe gene is a useful technique for detection of ethylene-producing bacteria.

In the current study, a PCR assay was used to examine 43 pathovars of $P$. syringae (78 strains) and other strains (79) of plant and insect origin for the presence of an efe gene. In addition, the possible plasmid location of efe genes was examined by Southern blot analysis. Finally, ethylene production by PCR-positive bacteria was verified by gas chromatography (GC) analysis.

\section{MATERIALS AND METHODS}

Bacterial strains and plasmids. The bacterial strains used in this study are listed in Tables 1 and 2. The total of 157 strains includes 43 pathovars of $P$. syringae, other plant-pathogenic and epiphytic bacteria, and bacteria of insect origin. A plasmid clone, pKEFE, containing the efe gene $(1.05 \mathrm{~kb})$ from strain PK2 cloned into pKK223-3, which was supplied by K. Nagahama, was used as a DNA probe for Southern blot hybridization. To estimate the molecular size of the indigenous plasmids, the following standard plasmid markers were used: three plasmids $(91,76$, and $38 \mathrm{~kb})$ of $P$. syringae pv. mori S6801 (14) and plasmid pBPW1::Tn7 (59 kb) of $P$. syringae pv. tabaci BR2 (15).

Bacterial culture. For PCR assay and plasmid isolation, bacteria were grown on modified Luria-Bertani (LB) agar medium ( $10 \mathrm{~g}$ of peptone, $5 \mathrm{~g}$ of yeast extract, $10 \mathrm{~g}$ of $\mathrm{NaCl}, 15 \mathrm{~g}$ of agar, and 1 liter of distilled water) or modified LB broth overnight at $28^{\circ} \mathrm{C}$, respectively. To detect ethylene production, the bacteria were cultured on King's medium B (KB) agar or in KB broth (7).

Plasmid DNA isolation. Plasmid DNA was extracted according to Birnboim and Doly (2) and separated by electrophoresis in Tris- 
borate buffer ( $0.89 \mathrm{M}$ Tris-borate, $0.089 \mathrm{M}$ boric acid, $\mathrm{pH} 8.0)$ at $8 \mathrm{~V} / \mathrm{cm}$ in $0.6 \%$ agarose gel for $3 \mathrm{~h}$.

PCR analysis. Two sets of primers were designed from the sequence of the efe gene of $P$. syringae pv. phaseolicola PK2 (4). To amplify the entire efe gene $(1.05 \mathrm{~kb})$, primers ETH-1 (5'ATGAC-

TABLE 1. Detection of ethylene-forming enzyme genes (efe) in 43 pathovars of Pseudomonas syringae by polymerase chain reaction (PCR) amplification

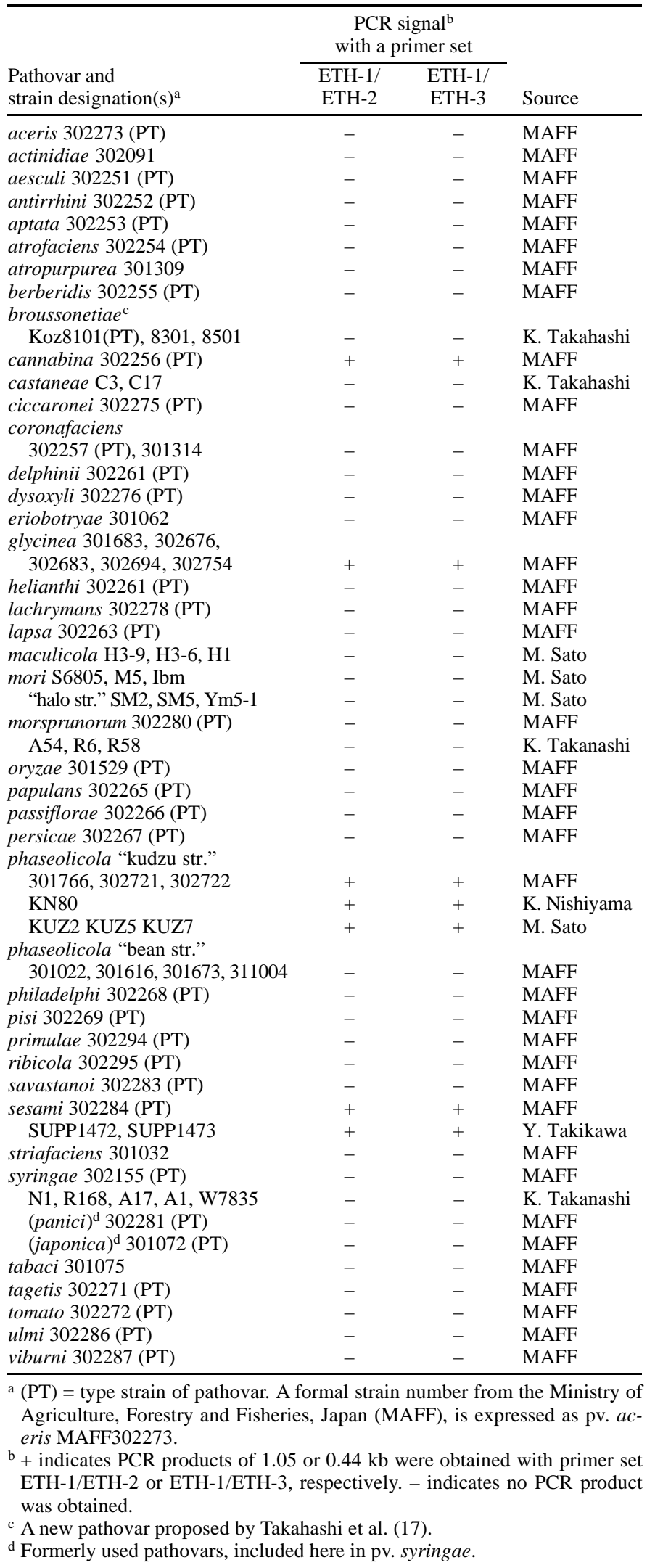

CAACCTACAGACT-3') and ETH-2 (5'-TCATGAGCCTGTCGCGCG-3') were used. To amplify a $0.44-\mathrm{kb}$ portion of the efe gene, primers ETH-1 and ETH-3 (5'-TAAGCCACCAACATCGTC-3') were used. Template DNAs were prepared by boiling a bacterial suspension $\left(10^{8} \mathrm{CFU} / \mathrm{ml}\right.$ in distilled water) for $5 \mathrm{~min}$. In some cases, plasmid DNAs, excised from gels with a Geneclean II kit (BIO 101 Inc., La Jolla, CA) according to the manufacturer's protocol, were used as template DNAs. The standard reaction mixture $(50 \mu \mathrm{l})$ contained $1.5 \mathrm{mM} \mathrm{MgCl}, 0.2 \mathrm{mM}$ each dNTP, 1.25 units of Taq DNA polymerase (Promega, Madison, WI), 25 pmol each primer, $5 \mu \mathrm{l}$ of $10 \times$ reaction buffer, and $2.5 \mu \mathrm{l}$ of boiled bacterial suspension. Amplification included 30 cycles of denaturation $\left(94^{\circ} \mathrm{C}\right.$ for $1 \mathrm{~min})$, annealing $\left(55^{\circ} \mathrm{C}\right.$ for $\left.2 \mathrm{~min}\right)$, and extension $\left(72^{\circ} \mathrm{C}\right.$ for $\left.3 \mathrm{~min}\right)$.

For PCR restriction fragment length polymorphism (RFLP) analysis, the PCR products were precipitated with 3 volumes of ethanol and resuspended in the appropriate restriction buffer. The purified PCR products were digested with various restriction enzymes and electrophoresed in $3.0 \%$ low melting temperature agarose gel $(\mathrm{Nu}-$ Sieve agarose, FMC Bioproducts, Rockland, MD) as described above.

Southern blot analysis. The entire pKEFE plasmid or efe gene (a PCR product from pKEFE obtained by primer set ETH-1/ETH-2) was labeled with a digoxigenin (DIG) DNA-labeling kit from Boehringer Biochemica (Mannheim, Germany) according to the manufacturer's protocol and used as a probe for Southern blot hybridization. Southern blot analysis was performed according to standard procedures (12) with some modifications. After electrophoresis, agarose gels were soaked in several volumes of $1.5 \mathrm{M}$ $\mathrm{NaCl}$ and $0.5 \mathrm{M} \mathrm{NaOH}$ for $30 \mathrm{~min}$ to denature DNA and in $0.5 \mathrm{M}$ Tris- $\mathrm{HCl}(\mathrm{pH} 8.0)$ and $1.5 \mathrm{M} \mathrm{NaCl}$ for $30 \mathrm{~min}$ to neutralize DNA.

TABLE 2. Bacterial strains of plant, insect, and other origins in which polymerase chain reaction (PCR) amplification with primer set ETH-1/ETH-2 did not detect ethylene-forming enzyme genes (efe) (1.05-kb product)

\begin{tabular}{ll}
\hline Strain and designation(s) & Source(s) \\
\hline Plant origin & \\
Acidovorax avenae $\mathrm{K} 3$ & I. Matsuda \\
Enterobacter cloacae Mul1 ${ }^{\mathrm{b}}$ & M. Sato \\
Erwinia ananas $301720,301718,301722$ & MAFF \\
TM2 & M. Sato \\
Erwinia herbicola DW1 & M. Sato \\
Erwinia herbicola pv. milletiae 301749 & MAFF \\
Pseudomonas cichorii NR7634 & I. Matsuda \\
P. fluorescens LRB3W1 & K. Tsuchiya \\
P. marginalis S-M & Y. Takikawa \\
P. viridiflava Ko8 & M. Sato \\
M328, M303 & K. Takahashi \\
Burkholderia andropogonis 301154 & MAFF \\
Burkholderia caryophylii 13525 & I. Matsuda \\
Burkholderia gladioli pv. gladioli NR8810 & I. Matsuda \\
Burkholderia plantarii 301723 & MAFF \\
Ralstonia solanacearum 301520,301522 & MAFF \\
Xanthomonas campestris pv. campestris 301151 & MAFF \\
pv. citri 301079 & MAFF \\
pv. oryzae 301225 & MAFF
\end{tabular}

Insect origin 50 strains M. Sato, K. Watanabe

Other origins

Alcaligenes faecalis $1474 \quad$ JCM

Bacillus cereus $2152 \quad$ JCM

Bacillus pumilus $2508 \quad$ JCM

Bacillus subtilis $1465 \quad$ JCM

SAT1 M. Sato

Clostridium butyricum $1391 \quad$ JCM

${ }^{a}$ Strains of insect origin include Erwinia herbicola, Erwinia ananas, Pseudomonas syringae, Serratia marcescens, Enterobacter cloacae, Micrococcus sp., Staphylococcus sp., and other unidentified bacteria. A formal strain number from the Ministry of Agriculture, Forestry and Fisheries, Japan (MAFF), or the Japan Collection of Microorganisms (JCM) is expressed as Xanthomonas campestris pv. oryzae MAFF301225 or Bacillus cereus JCM2152.

${ }^{\mathrm{b}}$ Isolated from mulberry. 
DNAs were transferred to nylon membrane filters from gels by capillary blotting. Filters were baked at high temperature $\left(120^{\circ} \mathrm{C}\right.$ for $1 \mathrm{~h}$ ). The baked filters were prehybridized in $20 \mathrm{ml}$ of prehybridization fluid ( $4 \times \mathrm{SSC}$ [ $1 \times \mathrm{SSC}$ is $0.15 \mathrm{M}$ sodium chloride plus $0.015 \mathrm{M}$ sodium citrate, $\mathrm{pH} 7.0$ ], $50 \%$ formamide, $0.1 \% \mathrm{~N}$ lauroylsarcosine sodium salt solution, $0.2 \%$ sodium dodecyl sulfate [SDS] solution, and $2 \%$ blocking reagent [Boehringer Biochemica]) and warmed to $43^{\circ} \mathrm{C}$ for $4 \mathrm{~h}$. DIG-labeled DNA (10 $\left.\mu \mathrm{l}\right)$ was added and hybridized overnight at $43^{\circ} \mathrm{C}$. After hybridization, the filters were washed once with $2 \times \mathrm{SSC}$ and $0.1 \%$ SDS at room temperature for $30 \mathrm{~min}$ and three times with $0.1 \times \mathrm{SSC}$ and $0.1 \%$ SDS at $65^{\circ} \mathrm{C}$ for $20 \mathrm{~min}$. Bands were detected by an enzyme-catalyzed chemiluminescence reaction with a DIG luminescent detection kit from Boehringer Biochemica according to the manufacturer's protocol.

Ethylene production. To detect ethylene production, bacteria were inoculated onto an agar slant of KB $(10 \mathrm{ml})$ in a test tube ( $15 \mathrm{~mm}, 32-\mathrm{ml}$ capacity) or in $\mathrm{KB}$ broth $(20 \mathrm{ml})$ in a $100-\mathrm{ml}$ flask. The tubes were sealed with a rubber serum cap and incubated with slow shaking (liquid medium) or without shaking (agar medium) at $25^{\circ} \mathrm{C}$ for 20 or $48 \mathrm{~h}$. A gas sample was withdrawn through the rubber seal with a gas-tight syringe and analyzed with a Hewlett Packard 5890-series II GC equipped with a GC-alumina capillary column $(50 \mathrm{~m} \times 0.53 \mathrm{~mm}$ inside diameter; Hewlett-Packard Co., Palo Alto, CA), 0.25- $\mu$ m thick film (J \& W Scientific, Folsom, CA), and a hydrogen flame ionization detector.

\section{RESULTS}

PCR detection. Five strains of $P$. syringae pv. glycinea (MAFF301683, 302676, 302683, 302694, and 302754) and seven

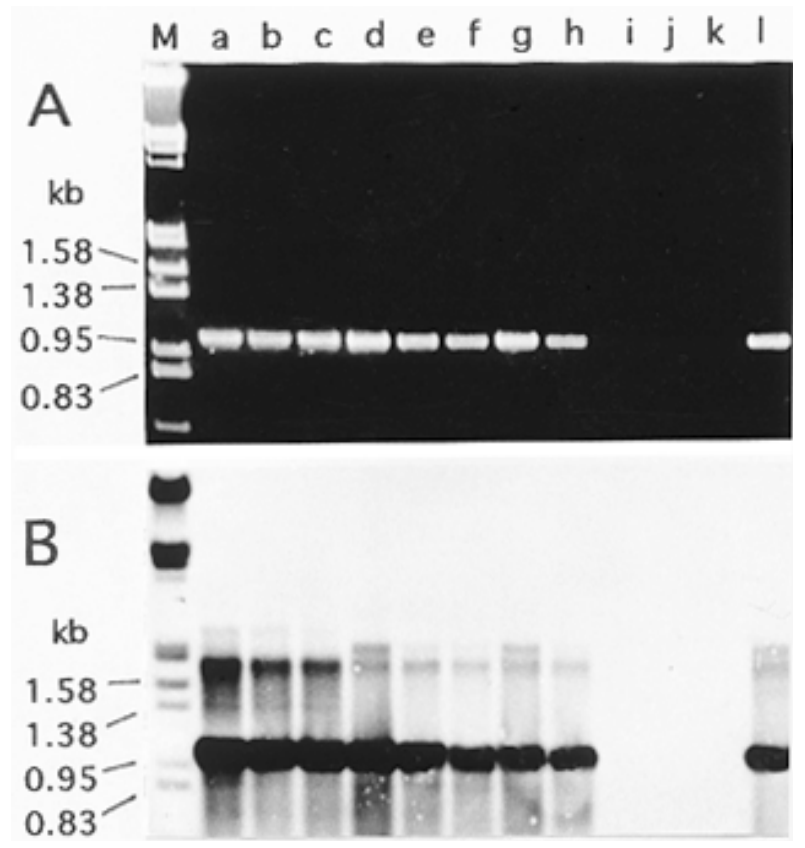

Fig. 1. A, Polymerase chain reaction (PCR) products from Pseudomonas syringae pathovars and Ralstonia solanacearum with primer set ETH-1/ETH-2 and B, Southern blot hybridization to the PCR products probed with the $P$. syringae pv. phaseolicola efe gene. Lane M, molecular size markers ( $\lambda$ DNA digested with HindIII and EcoRI); lane a, P. syringae pv. sesami strain MAFF302284; lane b, $P$. syringae pv. sesami strain SUPP1472; lane c, $P$. syringae pv. sesami SUPP1473; lane d, P. syringae pv. cannabina strain MAFF302256; strain e, $P$. syringae pv. glycinea strain MAFF301683; lane f, $P$. syringae pv. glycinea strain MAFF302676; lane g, P. syringae pv. phaseolicola strain KUZ2; lane h, $P$. syringae pv. phaseolicola strain MAFF301766; lane i, P. syringae pv. phaseolicola strain MAFF301022; lane $\mathrm{j}, R$. solanacearum strain MAFF301520; lane k, P. syringae pv. mori strain S6801; and lane 1, Escherichia coli strain JM109 (pKEFE). strains of $P$. syringae pv. phaseolicola (kudzu strain) (MAFF301766, 302721, 302722, KN80, KUZ2, KUZ5, and KUZ7), which are efficient ethylene producers $(6,16)$, were assayed by PCR with two sets of primers designed to amplify regions of the efe gene. All of the strains produced a band of the predicted size $(1.05 \mathrm{~kb}$ with ETH-1/ETH-2 or $0.44 \mathrm{~kb}$ with ETH-1/ETH-3), indicating these primer sets are suitable for detecting efe genes. A total of 157 strains, including 43 pathovars of $P$. syringae, were assayed. Using primer set ETH-1/ETH-2, only $P$. syringae pvs. cannabina and sesami produced a PCR product of the same size as that of $P$. syringae pvs. glycinea and phaseolicola (Fig. 1). In contrast, the other pathovars did not produce any PCR products. These positive strains were examined further with primer set ETH-1/ETH-3. All of the PCR-positive (ETH-1/EHT-2) pathovars produced a 0.44-kb band with ETH-1/ETH-3, unlike the PCR-negative strains (Table 1). Moreover, other bacterial strains, including those of insect and plant origin, did not produce any PCR products amplified by the primer set (ETH-1/ETH-2), as shown in Table 2. The efe probe hybridized with these PCR products, indicating amplified DNAs contain an efe gene (Fig. 1).

RFLP analysis. Strains of $P$. syringae pvs. cannabina MAFF302256, sesami MAFF302284, glycinea MAFF301683, and phaseolicola KUZ2 were used for PCR-RFLP analysis. PCR products from these strains were digested with restriction enzymes, such as HhaI, EcoRV, MspI, and HaeIII. As shown in Figure 2, similar RFLP patterns were obtained in all the samples, suggesting the efe genes of the four $P$. syringae pathovars are closely related.

Plasmid profiles and Southern blot analysis. Plasmid profiles of one strain of $P$. syringae pv. cannabina and three strains of $P$. syringae pv. sesami were compared with those of $P$. syringae pvs. glycinea and phaseolicola (kudzu strain). Numerous indigenous plasmids were detected in all of these strains (Fig. 3). The efe probe hybridized to only one plasmid in $P$. syringae pv. cannabina (the largest plasmid in Fig. 3, lane a), as well as to plasmids in $P$. syringae pvs. glycinea and phaseolicola $(\approx 105-$ and $\approx 68-\mathrm{kb}$ plasmids in Figure 3, lanes e and f, respectively) but did not hybridize to any plasmids in the $P$. syringae pv. sesami strains. These findings suggest that $P$. syringae pv. cannabina MAFF302256 harbors an "ethylene plasmid," whereas the efe gene is located on the chromosome in the three $P$. syringae pv. sesami strains used in this study. The molecular size of the ethylene plasmid of $P$. syringae

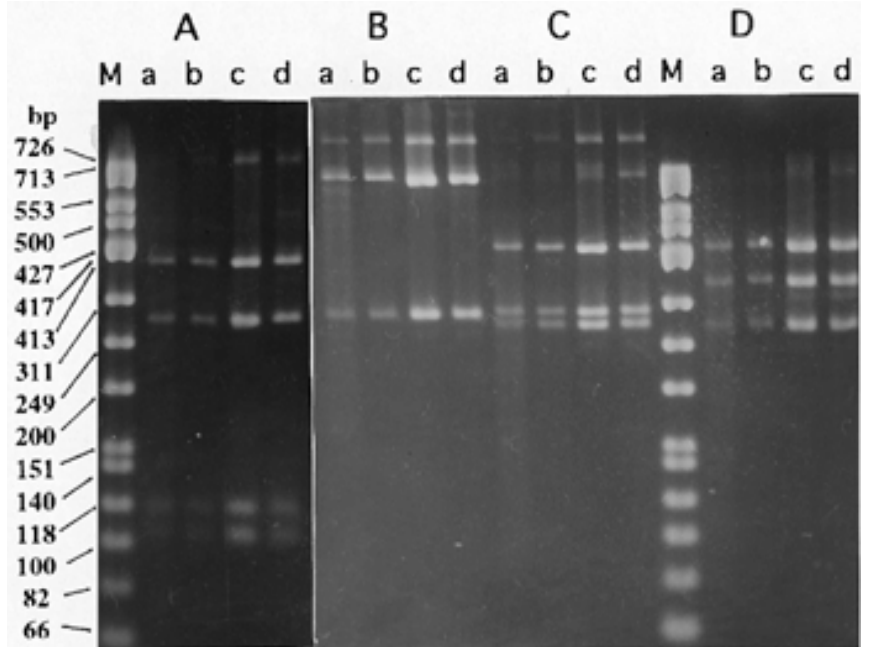

Fig. 2. Restriction fragment length polymorphism analysis of polymerase chain reaction products from Pseudomonas syringae pvs. sesami, cannabina, glycinea, and phaseolicola, using restriction enzymes A, HhaI, B, EcoRV, C, MspI, and D, HaeIII. Lane M, molecular size markers $(\phi \times 174$ DNA digested with HinfI); lane a, P. syringae pv. sesami strain MAFF302284; lane b, P. syringae pv. cannabina strain MAFF302256; lane c, P. syringae pv. glycinea strain MAFF301683; and lane d, P. syringae pv. phaseolicola strain KUZ2. 
pv. cannabina was estimated to be $\approx 110 \mathrm{~kb}$ and was designated pETH1 (Fig. 3). pETH1 DNA was excised from agarose gel and used as a PCR template. This generated a $1.05-\mathrm{kb}$ PCR product with primer set ETH-1/ETH-2, indicating this plasmid carries an efe gene.

Ethylene production. Three strains of $P$. syringae pv. sesami and one strain of $P$. syringae pv. cannabina were examined for ethylene production by GC analysis. All of the PCR-positive strains produced ethylene, whereas the PCR-negative strains did not. The amount of ethylene produced by each strain was determined relative to that produced by $P$. syringae pv. glycinea strain MAFF301683. Under conditions similar to those used here (20-h-old shake cultures in KB broth), Sato et al. (16) reported that this strain produced $69.2 \times 10^{-9} \mathrm{nl}$ per cell per h. P. syringae pvs. sesami and cannabina produced essentially the same amount of ethylene as strain MAFF301683. Relative amounts of ethylene, expressed as a ratio of the unknown to the standard strain, were as follows: $P$. syringae pv. sesami strains MAFF302284, 1.0; SUPP1472, 0.9; SUPP1473, 0.7; P. syringae pv. cannabina strain MAFF302256, 1.2; and $P$. syringae pv. phaseolicola (kudzu strain) MAFF302721, 1.1.

\section{DISCUSSION}

PCR amplification with primers containing sequences of the efe gene of $P$. syringae pv. phaseolicola PK2 (4) was a useful technique to detect ethylene-producing bacteria among a number of bacteria. PCR-positive strains produced ethylene very efficiently. PCR detection of the efe gene was first described by Weingart and Volksch (18). They found that all of the strains of $P$. syringae pvs. phaseolicola (kudzu strain) and glycinea that produced ethylene efficiently were PCR-positive. However, they could not detect any other new ethylene-producing bacteria among a large number of other strains. These findings suggest that the efe gene may be distributed in a very limited number of bacteria. Likewise, we showed that most of the bacterial strains in this study did not harbor an efe gene. However, we detected two new ethylene-producing $P$. syringae pathovars: cannabina and sesami. Interestingly, Weingart and Volksch (18) reported that a strain of $P$. syringae pv. cannabina did not produce ethylene. These findings suggest that $P$. syringae pv. cannabina strains may differ in ethylene-producing ability.

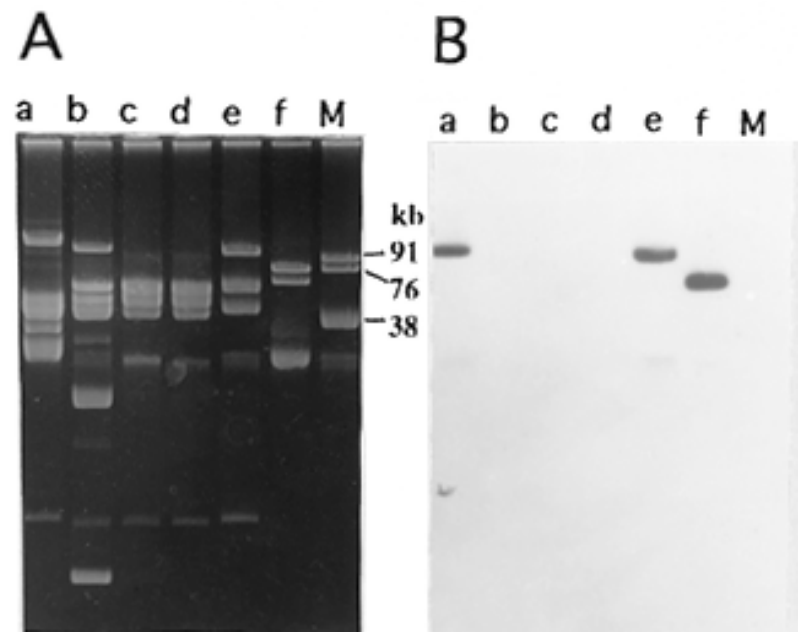

Fig. 3. A, Plasmid profiles of Pseudomonas syringae pathovars and B, Southern blot hybridization to plasmids with the $P$. syringae pv. phaseolicola efe probe. Lane a, $P$. syringae pv. cannabina strain MAFF302256; lane b, $P$. syringae pv. sesami strain MAFF302284; lane c, P. syringae pv. sesami strain SUPP1472; lane d, P. syringae pv. sesami strain SUPP1473; lane e, P. syringae pv. glycinea strain MAFF302676; lane f, P. syringae pv. phaseolicola strain MAFF301766; and lane M, molecular size markers (indigenous plasmids of $P$. syringae pv. mori strain S6801). The plasmid pBPW1::Tn7 (59 kb) also was used as a marker but is not shown. In Southern blot hybridization, strain S6801 plasmids were used as a negative control.
The same RFLP patterns were obtained for the efe gene in $P$. syringae pvs. cannabina, sesami, phaseolicola, and glycinea. In addition, the $P$. syringae pv. phaseolicola efe probe hybridized to PCR products from the other pathovars. Therefore, the efe genes amplified from these strains may be closely related to each other.

Nagahama et al. (11) reported that the efe gene was encoded by indigenous plasmids in $P$. syringae pvs. phaseolicola and glyci$n e a$. In the current study, we found that all the strains of $P$. syringae pvs. glycinea and phaseolicola tested harbored indigenous plasmids containing the efe gene, supporting the results of Nagahama et al. (11). Our data also indicate that $P$. syringae pv. cannabina may harbor an ethylene plasmid. The ethylene plasmids from the three pathovars varied in molecular size, which is not surprising because a similar size variation has been reported in the "coronatine plasmids" in several pathovars of $P$. syringae $(1,13,19)$. It is assumed that these ethylene plasmids may have been modified by cointegration or recombination with other plasmids. Interestingly, these pathovars, which harbor ethylene plasmids, can infect plants belonging to the family Leguminosae. $P$. syringae pv. cannabina infects Phaseolus vulgaris and Vicia sativa, as well as Cannabis sativa of the family Moraceae (8). This observation suggests that the ethylene plasmid may move via conjugation among strains of $P$. syringae that colonized Leguminosae plants in the past. Subsequently, the plasmid genes became established in strains of each pathovar. It is likely that ethylene production is advantageous for survival on Leguminosae plants. This assumption is supported by Weingart and Volksch (18), who concluded that ethylene production in planta may play an important role in the pathogenicity of $P$. syringae. In contrast, no strains of $P$. syringae pv. sesami appear to carry an autonomous ethylene plasmid, and the efe gene appears to be chromosomal (we could not detect any plasmids that hybridized to the efe probe). Strains of $P$. syringae pv. sesami are pathogenic to Sesamum indicum (sesame) in the family Pedaliaceae but not the family Leguminosae. The origin of the efe gene in $P$. syringae pathovars is still obscure. The gene may have been acquired from other microbial or plant genomes. As a result, $P$. syringae pv. sesami strains as well as other ethylene-producing pathovars may be useful in investigating the evolution of the efe gene and ethylene plasmids.

\section{ACKNOWLEDGMENTS}

This work was supported by a grant-in-aid from the Ministry of Agriculture, Forestry and Fisheries, Japan (MAFF). We thank K. Nagahama, Kumamoto Institute of Technology, for supplying the plasmid pKEFE and MAFF, K. Takahashi, K. Takanashi, K. Tsuchiya, and I. Matsuda for supplying bacterial stains.

\section{LITERATURE CITED}

1. Bender, C. L., Malvic, D. K., and Mitchell, R. E. 1989. Plasmid-mediated production of the phytotoxin coronatine in Pseudomonas syringae pv. tomato. J. Bacteriol. 171:807-812.

2. Birnboim, H. C., and Doly, J. 1979. A rapid alkaline extraction procedure for screening recombinant plasmid DNA. Nucleic Acids Res. 7:15131523.

3. Freebairn, H. T., and Buddendenhagen, I. W. 1964. Ethylene production by Pseudomonas solanacearum. Nature (Lond.) 202:313-314.

4. Fukuda, H., Ogawa, T., Ishihara, K., Fujii, T., Nagahama, K., Omata, T., Inoue, Y., Tanase, S., and Morino, Y. 1992. Molecular cloning in Escherichia coli, expression and nucleotide sequence of the gene for the ethylene-forming enzyme of Pseudomonas syringae pv. phaseolicola PK2. Biochem. Biophys. Res. Commun. 188:826-832.

5. Fukuda, H., Sakai, M., Nagahama, K., Fujii, T., Tanase, S., and Morino, Y. 1992. Heterologous expression of the gene for the ethylene-forming enzyme from Pseudomonas syringae in the cyanobacterium Synechococcus. Biotechnol. Lett.16:1-6.

6. Goto, M., Ishida, Y., Takikawa, Y., and Hyodo, H. 1985. Ethylene production by kudzu strains of Pseudomonas syringae pv. phaseolicola causing halo blight in Pueraria lobata (Willd.) Ohwi. Plant Cell Physiol. 26:141-150. 
7. King, E. O., Ward, M. K., and Raney, D. E. 1954. Two simple media for the demonstration of pyocyanin and fluorescein. J. Lab. Clin. Med. 44: 301-307.

8. Krieg, N. R., and Holt, J. H. 1984. Pseudomonas syringae. Pages 168172 in: Bergey's Manual of Systematic Bacteriology. Williams \& Wilkins, Baltimore.

9. Nagahama, K., Ogawa, T., Fujii, T., Tazaki, M., Goto, M., and Fukuda, H. 1991. L-Arginine is essential for the formation in vitro of ethylene by an extract of Pseudomonas syringae. J. Gen. Microbiol. 137:1641-1646.

10. Nagahama, K., Ogawa, T., Fujii, T., Tazaki, Tanase, S., Morino, Y., and Fukuda, H. 1991. Purification and properties of an ethylene-forming enzyme from Pseudomonas syringae. J. Gen. Microbiol. 137:2281-2286.

11. Nagahama, K., Yoshino, K., Matsuoka, M., Sato, M., Tanase, S., Ogawa, T., and Fukuda, H. 1994. Ethylene production by strains of the plant-pathogenic bacterium Pseudomonas syringae depends upon the presence of indigenous plasmids carrying homologous genes for the ethylene-forming enzyme. Microbiology 140:2309-2313.

12. Sambrook, J., Fritsch, E. F., and Maniatis, T. 1982. Plasmid vectors. Pages 1.1-1.110 in: Molecular Cloning: A Laboratory Manual. 2nd ed. Cold Spring Harbor Laboratory Press, Cold Spring Harbor, NY.

13. Sato, M., Nishiyama, K., and Shirata, A. 1983. Involvement of plasmid
DNA in the production of coronatine by Pseudomonas syringae pv. atropurpurea. Ann. Phytopathol. Soc. Jpn. 49:522-528.

14. Sato, M., Staskawicz, B. J., and Panopoulos, N. J. 1982. Indigenous plasmids of Pseudomonas syringae pv. mori, the causal agent of bacterial blight of mulberry. Ann. Phytopathol. Soc. Jpn. 48:27-33.

15. Sato, M., Staskawicz, B. J., Panopoulos, N. J., Peters, S., and Homma, M. 1981. A host-dependent hybrid plasmid suitable as a suicidal carrier for transposable elements. Plasmid 6:325-331.

16. Sato, M., Urushizaki, K., Nishiyama, K., Sakai, F., and Ota, Y. 1987. Efficient production of ethylene by Pseudomonas syringae pv. glycinea which causes halo blight in soybeans. Agric. Biol. Chem. 51:1177-1178.

17. Takahashi, K., Nishiyama, K., and Sato, M. 1996. Pseudomonas syringae pv. broussonetiae pv. nov., the causal agent of bacterial blight of paper mulberry (Brounssonetia kazinoki $\times$ B. papyrifera). Ann. Phytopathol. Soc. Jpn. 62:17-22.

18. Weingart, H., and Volksch, B. 1997. Ethylene production by Pseudomonas syringae pathovars in vitro and in planta. Appl. Environ. Microbiol. 63:156-161.

19. Zhu, Y., Tamura, K., Watanabe, M., Matsuda, I., and Sato, M. 1995. Plasmid-mediated coronatine production in Pseudomonas syringae pv. maculicola. Ann. Phytopathol. Soc. Jpn. 61:569-574. 